\title{
Empirical Analysis on Perceived Risk of Enterprise's Logistics Supervisor for Outsourcing Logistic Business
}

\author{
Jianhong Huang \\ Tourism College, Hainan University \\ Chongqing 570228, China \\ Aiguo Li \\ Management College, Chongqing Technology and Business University \\ Chongqing 570228, China
}

\begin{abstract}
According to the conceptual model established and assumptions put forward based on literature review as well as data collected through questionnaire survey, data reliability analysis, metric model confirmatory factor analysis and structural equation model analysis made by statistical software, it shows that enterprise's Logistics Supervisor has a definite risk perception for outsourcing logistic business.
\end{abstract}

Keywords: Enterprise's Logistics Supervisor Outsourcing Logistic Business, Risk Perception SEM

\section{Introduction}

The third party logistics service is a typical business outsourcing activity, where logistics services are provided for the supplier or the buyer partially or completely by a logistics enterprise other than the supplier and the buyer within a specified term in the form of contract. When an enterprise outsources the logistic business to the third party logistics service provider, on the one hand, operating risk can be reduced. On the other hand, various new potential risks may occur. Liu Lianhui(2006) thought that foreign enterprises attach great importance to outsourcing logistic business. One important reason of which American and Japanese enterprises are cautious in making decision for logistics outsourcing is various potential risks there. Therefore, discussion of risk issues also has great significance for development of the third party logistics market in our country.

\section{Literature review}

\subsection{The risk of outsourcing Logistic Business}

Foreign scholars generally believe that risks existing in business outsourcing include contract cost increase caused by disputes at law, proceedings and difficulty in contract negotiation, hidden cost increase such as service and management cost increase, etc. service quality decline, losing expertise and innovation ability and weakening the organizational competence (XuShu, 2003). Cui Nanfang et al (2006) classified the business outsourcing into decision-making and execution phases, and they believe that risks existing in outsourcing decision-making phase include limited rationality, contractor's opportunism, outsourcing transaction "locking", etc., and those existing in execution phase mainly concern moral risk, coordination issues, potential after-cost, etc.. Based on these, Peng Yulan (2004) believed that during the course of using the third party logistics by an enterprise, risks may result from loss of control rights, cooperation risk, etc.. Zeng Xiangyun (2004) believed that due to various reasons, such as exclusive supplier, principal-agent, enterprise cultural difference, IT technology limitation, information transfer, economic fluctuation, cooperative management, etc., risks may exist that both parties do not reach a common understanding, the supplier does not meet his commitments, there is a contradictory emotion inside the enterprise, it is difficult to satisfy the end customers' needs, termination clauses are lacking for profit loss, etc.. Li Songqing(2005) believed that, an enterprise that uses the third party logistics faces the risks of partial or complete loss of control rights, customer relation management, enterprise strategy disclosure, associate operation, opportunism, etc.. Wei Zhong et al.(2005) believed that risks existing in logistics outsourcing include management risk, information risk, financial risk and market risk.

\subsection{Customer perceived risk}

Bauer(1960) believes that customers' behaviors may result in unpredictable consequence, some of which are unpleasing. That is to say, various risks are hidden in customers' behaviors. In recent years, risk perception theory has been widely used for empirical study in the field of customers' behaviors by foreign scholars. Jacoby and Kaplan(1972)found that 
there were six kinds of risks including financial risk, performance risk, bodily risk, psychological risk, social risk and time-loss risk. Stone and Gronhaug (1993) have validated the existence of six risk dimensions. Lim(2003) has summarized the previous study on risk perception, and classified the risks into nine aspects. The nine kinds of risks respectively are perceived financial risk, perceived performance risk, perceived social risk, perceived physical risk, perceived psychological risk, perceived time-loss risk, perceived personal risk, perceived privacy risk and perceived source risk.

\section{Conception model and research hypothesis}

According to the study of foreign scholars and combining the characteristics of logistic business outsourcing, we believe that the enterprise's Logistics Supervisor may have some risk perception for risks existing in outsourcing logistic business to a logistics company, and have some concern about that whether logistics services can really satisfy the enterprise's requirements or not. In this article, we mainly study perceived control right risk, perceived performance risk, perceived financial risk and perceived social psychological risk, of which perceived control right risk mainly reflects his concern about logistics activities being out of his own control; perceived performance risk mainly reflects his concern about the logistics function and performance losses that may be brought to his enterprise arising from quality problems of the logistics services provided by logistics company; perceived financial risk reflects his concern about the financial and economic losses that may be brought to his enterprise by logistics company; perceived social psychological risk reflects his concern about his social psychological stress arising from various losses that may be brought by logistics company.

In fact, when an enterprise outsources partial or complete logistics function to a logistics company, it means that the enterprise cannot directly control its partial or complete logistics function, and therefore cannot control logistics services as well as service quality and level therefrom. Meanwhile, when an enterprise gives up the application and development of its logistics technologies, it may become a logistics company-dependent enterprise to a certain extent, which increases the uncertainty of production and service of the enterprise. From the point of view of the enterprise itself, when logistics is outsourced, it is difficult to guarantee the supply accuracy, punctuality and safety so that the end customer service quality can not be ensured. In addition, third party logistics service in fact is series of principal-agent relationship based on credit system, which causes the risks such as the lower stability of the third party logistics service provider, logistics service quality decline, failure to meet the previous commitments, etc..

Therefore, it is the performance risk and financial risk of the enterprise arising from its outsourcing logistic business to logistics company that bring social psychological stress to the enterprise's Logistics Supervisor. Based on these,we propose following research hypothesis:

H1: There is a positive relationships between enterprise's logistics supervisor's Perceived control right risk and perceived performance risk.

H2: There is a positive relationships between enterprise's logistics supervisor's Perceived control right risk and perceived financial risk.

H3: There is a positive relationships between enterprise's logistics supervisor's Perceived control right risk and perceived social psychological risk.

H4: There is a positive relationships between enterprise's logistics supervisor's perceived performance risk and perceived social psychological risk.

H5: There is a positive relationships between perceived financial risk and perceived social psychological risk.

Moreover, Sanjeev Agarwal and Kenneth Teas (2001)believed that there is a positive relationships between customer perceived performance risk and perceived financial risk.So,we believe that enterprise's logistics supervisor's perceived performance risk aggravate his perceived financial risk. Therefore,we propose the last hypothesis of this article.

H6: There is a positive relationships between enterprise's logistics supervisor's perceived performance risk and perceived financial risk.

The conception model of this article being presented in following section.(see Figure 1)

Insert Figure 1 Here

\section{Questionnaires and data collection}

After in-depth literature study, we interviewed some experts. Based on this, we designed the first draft of the questionnaire, and finalized it after investigation. For perceived performance risk and perceived financial risk measurements, we mainly refer to Sweeney et al (1999); For perceived social psychological risk measurement, we mainly refer to Stone and Gronhaug (1993); For perceived control right risk, we put forward four measurement items through interview on the basis of relevant literature study (see: Appendix:I).We use seven point scales in this article.

By adopting convenience samples, we made a questionnaire survey for small and medium business and trade enterprises 
and manufacturing ones in Chengdu and Chongqing. Total 750 questionnaires were issued, and 205 effective questionnaires were obtained. The effective rate is $27.33 \%$.

\section{Data Analysis}

\subsection{Descriptive statistics}

We calculated the Mean and Standard deviation of all Variables using SPSS11.5, the result as following (see Table 1): Insert Table 1 Here

\subsection{Analysis of scale reliability}

We worked out the internal consistency coefficient of the evaluating indicator using SPSS software. The calculation results are shown in Table $2 . \alpha$ value is greater than 0.7 , which indicates that data reliability is relatively high.

Insert Table 2 Here

\subsection{Measurement model confirmation factor analyze}

We at first converted data into covariance matrix using PRELIS program of LISREL statistical software, and then conducted confirmatory factor analysis on each latent variable using LISREL program. Fitting degree indicators reached the satisfactory level on the whole, of which, chi-square value $=295.70, \mathrm{df}=99, \chi^{2} / \mathrm{df}<5, \mathrm{RMSEA}=0.099$, $\mathrm{SRMR}=0.055, \mathrm{NFI}=0.94, \mathrm{NNFI}=0.95, \mathrm{CFI}=0.96, \mathrm{IFI}=0.96, \mathrm{RFI}=0.93$. Factor loadings of all indicators on respective measurement concept (latent variable) are relatively significant. All $t$ values are much greater than the critical value 1.96. Standardized estimated value is all situate between 0.5-0.95. No major measurement error occurred (see table $3)$. Therefore, convergance valid of these data is relatively high.

Insert Table 3 Here

\subsection{Structure equation model analysis}

To test the relationships among four kinds of perceived risk, we use LISREL8.54to analysis the Structure equation model of this article. Though the RMSEA beyond $0.08, \chi 2 / \mathrm{df}<5$, NFI, NNFI, CFI, IFI and RFI are all above 0.90 , this indicates that Model fitness is good. Through empirical analysis, we found that the relationships among four kinds of perceived risk we had proposed being proven to be true. Perceived control right risk has positive influence on perceived performance risk, perceived financial risk and perceived social psychological risk, these coefficients are $0.55,0.49$ and 0.25 , the result supports $\mathrm{H} 1, \mathrm{H} 2$ and $\mathrm{H} 3$; Perceived performance risk has positive influence on perceived financial risk and perceived social psychological risk, these coefficients are 0.31 and 0.29 , the result supports $\mathrm{H} 4$ and H5; Perceived financial risk has weakly influence on perceived social psychological risk, this coefficient is 0.07 , the result don't support H6. (See Table 4)

Insert Table 4 Here

\section{Discussion and Conclusion}

\subsection{Discussion}

Through empirical analysis, this paper demonstrates that the enterprise's Logistics Supervisor has relatively definite risk perception for outsourcing logistic business. From their point of view, when an enterprise partially or completely outsources its logistics business to a logistics company, the logistics services provided by the logistics company may fail to reach the standard specified in logistics outsourcing contract, which makes the logistics activity effect of the enterprise fail to meet the expected objective and brings performance loss and economic loss to the enterprise. Accordingly, perceived control right risk, perceived performance risk, perceived financial risk and perceived social psychological risk become the focus.

Furthermore, the internal relation and influence exists among the four kinds of risk perception. Perceived control right risk has positive influence on perceived performance risk, perceived financial risk and perceived social psychological risk. Perceived performance risk is a important consequent risk, the more the perceived performance risk, the more perceived financial risk and perceived social psychological risk. Risks that may cause economic loss have rather weak influence on social psychological risk perception of the enterprise's Logistics Supervisor, which perhaps attributes to their confidence in compensation for economic loss explicitly stipulated in the logistics outsourcing contract signed with the logistics company.

Therefore, outsourcing risk issues are very important to an enterprise's Logistics Supervisor. After logistics outsourcing, when an enterprise is able to know the basic information about the details of logistics operation through certain mechanism and means, and further can regulate and control the logistics activities and make them satisfy its requirements, the concern of the enterprise's Logistics Supervisor about various risks arising from outsourcing logistic business may be greatly abated.

Information communication frequency and quality between enterprises plays an important role in mutual understanding 
about each other's objective and taking concerted actions. Lack of, or inadequate exchange and communication makes it difficult for both parties to understand what benefits the other party expects to obtain from the cooperation and what objective the other party expects to meet. Trust mechanism should be established between the logistics company and the enterprise to strengthen the enterprise's confidence in logistics company, make the enterprise believe that the logistics company will faithfully perform the logistics service clauses stipulated in the contract, be able and try to solve the logistics problems of the enterprise, be willing to help the enterprise to realize its objective, and at the same time strengthen the communication with the enterprise and realize share of various information, including strategic factors such as the enterprise's task, business target, logistics task and logistics target, etc.. Effective communication and trust may reduce people's risk perception to a certain extent, and give a feeling to the enterprise's Logistics Supervisor that the logistics is still under control so that he is willing to accept the third party logistics services.

\subsection{Contribution}

Risk issue is one of the important factors that impede the growth of logistics service market. However, at present scholars neither have discussed logistics service risk from the point of view of customers, nor have made empirical study on risk issues caused by third party logistics from the point of view of customers' perception through questionnaire survey. This paper uses the customers' risk perception theory for empirical analysis on logistics customers' risk perception for the first time.

Secondly, in the field of customers' behavior theory study, scholars always regard the financial risk perception, performance risk perception and social psychological risk perception as the internal structure of risk perception. Only a few scholars such as Sanjeev Agarwal and Kenneth Teas (2001) has put forward and validated the viewpoint that customers' performance risk perception has direct and positive influence on customers' financial risk perception. At present scholars made no empirical study on internal relationship and influence among these three kinds of risk perception. In this article, we propose the relationships of perceived control right risk, perceived performance risk, perceived financial risk and perceived social psychological risk, and all the six research hypothesis being proven to be true through empirical analysis.

\subsection{Insufficiency of our Research}

This study has made a methodological innovation in the field of logistics customers' behavior study, whereas there are following two limitations in theoretical and empirical aspects: (1) Samples used in this study come from Chengdu and Chongqing, and are convenience samples. Whether it is applicable to other regions needs further discussion. (2) There still is no unified definition for customers' risk perception dimensions. Some scholars summarize them into nine aspects. This study has only discussed four of them. Other aspects are not discussed in this paper.

\subsection{Recommendations for Future Research}

The future study may be conducted from the following three aspects: (1) Continue to study other aspects of the customers' risk perception, and investigate their relationship. (2) Carry out questionnaire survey in a wider range and expand to other industries in order to test the general practicability and generalization value of this study result. (3) Risk perception of middle-aged and young Logistics Supervisors may vary from those in other ages. Make a comparative analysis on the survey results between the middle-aged and young Logistics Supervisors and those in other ages to further discover their risk perception for logistics outsourcing.

\section{References}

Bettman J.R. (1973). Perceived risk and its components: a model and empirical test.Journal of marketing research. (may), 184-190.

Carmen Lagesa, Cristiana Raquel Lagesb, Luis Filipe Lagesc. (2005). The RELQUAL scale: a measure of relationship quality in export market ventures, Journal of Business Research, 58, 1040- 1048.

Chaudhuri. (1998). A Product class efects on perceived risk: the role of emotion. International journal of research in marketing, (15), 157-168.

Cui Nanfang, Kang Yi and Lin Shuxian. (2006). Business outsourcing and guarding against the risk, Management science, (1), 44-49.

Derbaix. C. (1983). Perceived risk and risk relievers: an empirical investigation. Journal of economic psychology. (3), $19-38$.

Jacoby, J. and Kaplan, L. (1972). The components of perceived risk, in Venkatesan, M.(Ed.), Proceedings of the 3nt Annual Conference, Association for Consumer Research, Chicago, IL, 382-393.

Journal of Marketing Theory and Practice; Fall 2001; 9, 4; ABI/INFORM Global,1-14.

Li Songqing. (2005). Comments on a third party logistics, Beijing, Chinese goods and materials press. 
Liu Lianhui, Economics explanation of logistics outsoucing risk, China circulating economy, 2006,4, 13-15.

Nena Lim. (2003). Consumers' perceived risk: sources versus consequences, Electronic Commerce Research and Applications ,2, 216-228.

PengYulan. (2004). Third party logistics and risk, Commerce study, 24, 147-150.

Sanjeev Agarwal, R Kenneth Teas. Perceived value: Mediating role of perceived risk.

Stone, R. N. and Gronhaug, K. (1993). Perceived risk: further considerations for the marketing discipline, European Journal of Marketing, Vo1.27 No.3, 39-50.

Sweeney, J.C., Soutar,G.N., Johnson, L.W.(1999). The role of perceived risk in the quality-value relationship: A study in a retail environment. Journal of Retailing, 75(1), 77-105.

Wei Zhong, Shen Jinsheng, ChenJijun, Zhang Zhiwen. (2005). The Mechanism of logistics outsourcing risk of and keeping watch, The journal of China's security, (1), 55-58.

Xu Shu. (2003). Reviews of business outsourcing research result in West, Foreign economy and administration, (12), 13-17.

Zeng Xiangyun. (2004). Third party logistics collaboration and guarding against the risk, China circulating economy,7, $15-18$

\section{Appendix: I Questionnaires}

Q1:This TPL supplier does not serve well affecting our customer's benefit .

Q2: This TPL supplier does not serve well damaging our company's reputation.

Q3: This TPL supplier does not serve well affecting my prospects.

Q4: This TPL supplier does not serve well affecting my prestige.

Q5: This TPL supplier's service will increase our logistics cost.

Q6: This TPL supplier's service will bring economic losses to our company.

Q7: This TPL supplier's service will increase our monitor cost.

Q8: This TPL supplier's service will increase our customer service cost.

Q9: This TPL supplier does not offer high quality service.

Q10: This TPL supplier does not run well.

Q11: This TPL supplier does not offer consistent service.

Q12: Error will happen in the service process.

Q13: This TPL supplier will adopt opportunism behavior.

Q14: This TPL supplier will control our logistics business.

Q15: This TPL supplier will take advantage of our company's weaknesses.

Q16: This TPL supplier will break promise. 
Table1. Mean and Standard deviation of Variables

\begin{tabular}{|l|l|l|l|}
\hline Variable & Indicator & Mean & Standard deviation \\
\hline \multirow{5}{*}{$\eta 1$} & Q13 & 5.1756 & 1.1107 \\
\cline { 2 - 4 } & Q14 & 4.9220 & 1.1520 \\
\cline { 2 - 4 } & Q15 & 4.4293 & 1.2838 \\
\cline { 2 - 4 } & Q16 & 4.1598 & 1.2123 \\
\hline \multirow{5}{*}{$\eta 2$} & Q9 & 4.2122 & 1.1484 \\
\cline { 2 - 4 } & Q10 & 4.0511 & 1.1349 \\
\cline { 2 - 4 } & Q11 & 4.0880 & 1.1199 \\
\cline { 2 - 4 } & Q12 & 4.2223 & 1.2949 \\
\hline \multirow{5}{*}{73} & Q5 & 4.5902 & 1.4100 \\
\cline { 2 - 4 } & Q6 & 4.3822 & 1.3651 \\
\cline { 2 - 4 } & Q7 & 4.5862 & 1.4030 \\
\cline { 2 - 4 } & Q8 & 4.5573 & 1.3975 \\
\hline \multirow{5}{*}{$\eta 4$} & Q1 & 4.2488 & 1.3939 \\
\cline { 2 - 4 } & Q2 & 3.70529 & 1.4896 \\
\cline { 2 - 4 } & Q3 & 3.6990 & \\
\cline { 2 - 4 } & Q4 & & 1.6275 \\
\hline
\end{tabular}

Table 2. Cronbach $\alpha$ Value

\begin{tabular}{|l|l|l|}
\hline Variable & Indicator & Cronbach $\alpha$ \\
\hline$\eta 4$ & Q1-Q4 & 0.8683 \\
\hline$\eta 3$ & Q5-Q8 & 0.8811 \\
\hline$\eta 2$ & Q9-Q12 & 0.8872 \\
\hline$\eta 1$ & Q13-Q16 & 0.8745 \\
\hline Total Cronbach $\alpha: 0.9140$ & \multicolumn{2}{|l}{} \\
\hline
\end{tabular}

Table 3. factor loadings of all indicators on respective latent variable

\begin{tabular}{|l|l|l|l|l|}
\hline Relationships & Coefficient & $\begin{array}{l}\text { Standardized estimated } \\
\text { value }\end{array}$ & $\mathrm{t}$ & Measuring error \\
\hline$\eta 1 \rightarrow \mathrm{Q} 13$ & $\lambda(\mathrm{X}) 13,1$ & 0.79 & ---- & 0.38 \\
\hline$\eta 1 \rightarrow \mathrm{Q} 14$ & $\lambda(\mathrm{X}) 14,1$ & 0.87 & 13.47 & 0.25 \\
\hline$\eta 1 \rightarrow \mathrm{Q} 15$ & $\lambda(\mathrm{X}) 15,1$ & 0.85 & 13.23 & 0.27 \\
\hline$\eta 1 \rightarrow \mathrm{Q} 16$ & $\lambda(\mathrm{X}) 16,1$ & 0.80 & 12.25 & 0.36 \\
\hline$\eta 2 \rightarrow \mathrm{Q} 9$ & $\lambda(\mathrm{Y}) 9,2$ & 0.81 & ---- & 0.35 \\
\hline$\eta 2 \rightarrow \mathrm{Q} 10$ & $\lambda(\mathrm{Y}) 10,2$ & 0.89 & 12.69 & 0.22 \\
\hline$\eta 2 \rightarrow \mathrm{Q} 11$ & $\lambda(\mathrm{Y}) 11,2$ & 0.89 & 14.85 & 0.21 \\
\hline$\eta 2 \rightarrow \mathrm{Q} 12$ & $\lambda(\mathrm{Y}) 12,2$ & 0.79 & 12.69 & 0.37 \\
\hline$\eta 3 \rightarrow \mathrm{Q} 5$ & $\lambda(\mathrm{Y}) 13,3$ & 0.87 & ---- & 0.24 \\
\hline$\eta 3 \rightarrow \mathrm{Q} 6$ & $\lambda(\mathrm{Y}) 6,3$ & 0.94 & 19.61 & 0.12 \\
\hline$\eta 3 \rightarrow \mathrm{Q} 7$ & $\lambda(\mathrm{Y}) 7,3$ & 0.90 & 18.22 & 0.19 \\
\hline$\eta 3 \rightarrow \mathrm{Q} 8$ & $\lambda(\mathrm{Y}) 8,3$ & 0.62 & 10.04 & 0.61 \\
\hline$\eta 4 \rightarrow \mathrm{Q} 1$ & $\lambda(\mathrm{Y}) 1,4$ & 0.76 & ---- & 0.42 \\
\hline$\eta 4 \rightarrow \mathrm{Q} 2$ & $\lambda(\mathrm{Y}) 2,4$ & 0.77 & 11.38 & 0.41 \\
\hline$\eta 4 \rightarrow \mathrm{Q} 3$ & $\lambda(\mathrm{Y}) 3,4$ & 0.91 & 13.17 & 0.18 \\
\hline$\eta 4 \rightarrow \mathrm{Q} 4$ & $\lambda(\mathrm{Y}) 4,4$ & 0.80 & 11.69 & 0.36 \\
\hline
\end{tabular}


Table 4.

\begin{tabular}{|l|l|l|l|}
\hline Relationships & Coefficient & Standardized estimated value & $\mathrm{t}$ \\
\hline$\eta 1 \rightarrow \eta 2$ & $\beta 2,1$ & 0.55 & 7.29 \\
\hline$\eta 1 \rightarrow \eta 3$ & $\beta 3,1$ & 0.49 & 6.50 \\
\hline$\eta 1 \rightarrow \eta 4$ & $\beta 4,1$ & 0.25 & 2.48 \\
\hline$\eta 2 \rightarrow \eta 3$ & $\beta 3,2$ & 0.31 & 4.28 \\
\hline$\eta 2 \rightarrow \eta 4$ & $\beta 4,2$ & 0.29 & 3.13 \\
\hline$\eta 3 \rightarrow \eta 4$ & $\beta 4,3$ & 0.07 & 0.58 \\
\hline Model fit index & $\begin{array}{l}\chi 2=296.02 ; \mathrm{df}=98 ; \chi 2 / \mathrm{df}<5 ; \text { RMSEA }=0.100 ; \mathrm{SRMR}=0.055 ; \mathrm{NFI}=0.94 ; \mathrm{NNFI}=0.95 ; \mathrm{IFI}= \\
\end{array}$ & $0.96 ; \mathrm{RFI}=0.93 ; \mathrm{CFI}=0.96$. \\
\hline
\end{tabular}

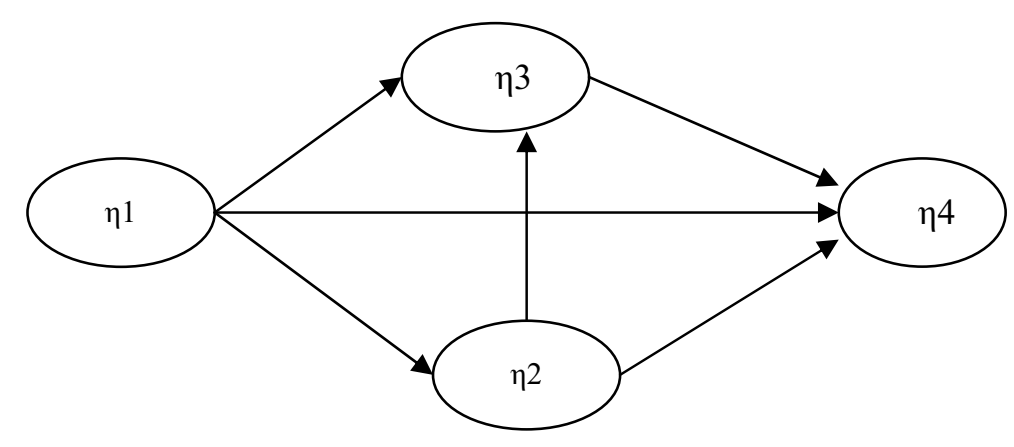

Figure 1. conception model

$\eta 1$ : Perceived control right risk; $\eta 2$ : perceived performance risk; $\eta 3$ : perceived financial risk; $\eta 4$ : perceived social psychological risk. 